\title{
Calcium-Permeable AMPA Receptors Provide a Common Mechanism for LTP in Glutamatergic Synapses of Distinct Hippocampal Interneuron Types
}

\author{
Andras Szabo, ${ }^{1}$ Jozsef Somogyi, ${ }^{2}$ Bruno Cauli, ${ }^{3}$ Bertrand Lambolez, ${ }^{3}$ Peter Somogyi, ${ }^{2}$ and Karri P. Lamsa ${ }^{1}$ \\ ${ }^{1}$ Department of Pharmacology, Oxford University, Oxford OX1 3QT, United Kingdom, ${ }^{2}$ Medical Research Council Anatomical Neuropharmacology Unit, \\ Oxford University, Oxford OX1 3TH, United Kingdom, and ${ }^{3}$ Neurobiologie des Processus Adaptatifs, CNRS UMR7102, Université Pierre et Marie Curie-P6, \\ 75005 Paris, France
}

\begin{abstract}
Glutamatergic synapses on some hippocampal GABAergic interneurons exhibit activity-induced long-term potentiation (LTP). Interneuron types within the CA1 area expressing mutually exclusive molecular markers differ in LTP responses. Potentiation that depends on calcium-permeable (CP) AMPA receptors has been characterized in oriens-lacunosum moleculare (0-LM) interneurons, which express parvalbumin and somatostatin (SM). However, it is unknown how widely CP-AMPAR-dependent plasticity is expressed among different GABAergic interneuron types. Here we examine synaptic plasticity in rat hippocampal 0-LM cells and two other interneuron types expressing either nitric oxide synthase (NOS) or cholecystokinin (CCK), which are known to be physiologically and developmentally distinct. We report similar CP-AMPAR-dependent LTP in NOS-immunopositive ivy cells and SM-expressing 0-LM cells to afferent fiber theta burst stimulation. The potentiation in both cell types is induced at postsynaptic membrane potentials below firing threshold, and induction is blocked by intense spiking simultaneously with afferent stimulation. The strong inward rectification and calcium permeability of AMPARs is explained by a low level of GluA2 subunit mRNA expression. LTP is not elicited in CCK-expressing Schaffer collateralassociated cells, which lack CP-AMPARs and express high levels of the GluA2 subunit. The results show that CP-AMPAR-mediated synaptic potentiation is common in hippocampal interneuron types and occurs in interneurons of both feedforward and feedback inhibitory pathways.
\end{abstract}

\section{Introduction}

Glutamatergic synapses exhibit activity-induced long-term potentiation (LTP) in some hippocampal GABAergic interneurons. Different forms of LTP have been reported in GABAergic cells, but it is unknown how the underlying plasticity mechanisms correlate with the different types of interneurons as characterized by their anatomy and expression of defined neurochemical markers. It has been shown that GABAergic cell types immunopositive for parvalbumin (PV) in the hippocampal CA1 area exhibit NMDAR-independent LTP, whereas those expressing cholecystokinin (CCK) and cannabinoid receptor type 1 (CB1R) fail to show this form of plasticity (Perez et al., 2001; Oren et al., 2009; Nissen et al., 2010). LTP

\footnotetext{
Received Jan. 14, 2012; revised Feb. 29, 2012; accepted March 21, 2012.

Author contributions: J.S., B.C., B.L., and K.P.L. designed research; A.S., B.C., B.L., and K.P.L. performed research; B.C., B.L., and P.S. contributed unpublished reagents/analytic tools; A.S., J.S., B.C., B.L., P.S., and K.P.L. analyzed data; K.P.L. wrote the paper.

This work was supported by the Wellcome Trust and The John Fell Fund (A.S., K.L.), Medical Research Council (J.S., P.S), and the Human Frontier Science Program (B.C, B.L.). We thank Douglas Asede, Dr. Damien Lapray, Wiebke Nissen, and Ben Micklem for help with anatomical analysis and illustration of ivy cells, and help with microscopic techniques. We acknowledge Drs. Etienne Herzog and Odile Poirel for help with GluA1- 4 quantification. We thank Drs. Colin Akerman, Ray Guillery, Thomas E. Holden, Dimitri Kullmann, and Stephanie Schorge for comments on the manuscript.

Correspondence should be addressed to Karri P. Lamsa, Department of Pharmacology, Oxford University, Mansfield Road, 0xford 0X130T, United Kingdom. E-mail: karri.lamsa@pharm.ox.ac.uk.

DOI:10.1523/JNEUROSCI.0206-12.2012

Copyright $\odot 2012$ the authors $\quad 0270-6474 / 12 / 326511-06 \$ 15.00 / 0$
}

depending upon activation of calcium-permeable (CP) AMPARs has been characterized in a subset of PV-expressing neurons known as oriens-lacunosum moleculare (O-LM) cells (Oren et al., 2009). Further reports have confirmed the importance of CPAMPARs for LTP in other PV-expressing interneuron types (Nissen et al., 2010; Polepalli et al., 2010; Sambandan et al., 2010). However, it is unknown whether CP-AMPARs endow other interneurons with similar mechanisms of synaptic plasticity. Here we have studied NMDAR-independent LTP in three interneuron types of CA1 area, similar in that their axons all innervate dendritic domain of pyramidal cells, but different in their expression of neurochemical markers. The results show that CP-AMPARmediated potentiation occurs in specific interneuron types, which are anatomically diverse and neurochemically different. We speculate that the similar plasticity in ivy and O-LM cells reflects their related activity patterns in vivo.

\section{Materials and Methods}

Hippocampal slices. Hippocampal slices were prepared from 3- to 4-week-old male Sprague Dawley rats, and recordings were performed in a submerged slice chamber (Oren et al., 2009). The perfusion medium contained the following (in $\mathrm{mm}$ ): $\mathrm{NaCl}$ (119), $\mathrm{KCl}$ (2.5), $\mathrm{CaCl}_{2}$ (2.5), $\mathrm{MgSO}_{4}$ (1.3), $\mathrm{NaH}_{2} \mathrm{PO}_{4}$ (1.25), $\mathrm{NaHCO}_{3}$ (25), glucose (11), final pH 7.4 (equilibrated with $\left.95 \% \mathrm{O}_{2} / 5 \% \mathrm{CO}_{2}\right)$. DL-AP5 $(100 \mu \mathrm{M})$, picrotoxin (100 $\mu \mathrm{M})$, CGP $55845(1 \mu \mathrm{M})$, and cannabinoid receptor type-1 blocker AM$251(1 \mu \mathrm{M})$ were present in all experiments. Chemicals were purchased from Sigma-Aldrich, and drugs from Tocris Cookson. 
Electrophysiology and analysis. Sequential gramicidin $(50-150 \mu \mathrm{g} / \mathrm{ml}$ in K-gluconate filling solution with $5 \mathrm{~mm}$ QX314-Br) perforated patchwhole-cell recordings were obtained as described previously (Oren et al., 2009). The whole-cell filling solution contained the following (in $\mathrm{mm}$ ): CsCl (145), HEPES (20), Cs-EGTA (0.2), $\mathrm{NaCl}$ (8), Mg-ATP (2), GTP (0.3), QX-314 Br (5), and spermine (0.2), pH 7.2 (290 mOsm/L). Data were low-pass filtered $(4-5 \mathrm{kHz})$ and acquired at $20 \mathrm{kHz}$ on a PC for analysis. EPSP initial slopes (3-5 ms from onset) were analyzed with the Student's paired and unpaired $t$ tests. Single-shock stimuli (100 $\mu$ s, with concentric bipolar electrode) were applied every $15 \mathrm{~s}$ to a pathway. Theta-modulated high-frequency burst stimulation (TBS) contained four bursts of five pulses at $100 \mathrm{~Hz}$ with an interval of 250 ms between bursts. This was repeated a total of 10 times with 20 s intervals. Postsynaptic membrane potential was free to fluctuate in current-clamp (liquid junction potential not corrected). Steps of $1 \mathrm{~s}$ depolarizing current were simultaneously applied for some cells. Numbers of spikes triggered during TBS were counted from $250 \mathrm{~ms}$ episodes in $10 \mathrm{~ms}$ bins. The mean of means for individual cells was plotted in the spiking histograms. For coefficient of variation (CV) analysis, values were taken from a $10 \mathrm{~min}$ recording period before and at 20-30 min after TBS.

Tissue processing and anatomical analysis. Neurons were filled with neurobiotin $(0.2-0.5 \%)$ during whole-cell recordings and fixed. Epifluorescent images of cells visualized by streptavidin-fluorochrome (Alexa Fluor 488 or indocarbocyanine $\mathrm{Cy} 3$ ) were digitally recorded from 70 $\mu \mathrm{m}$-thick sections (Oren et al., 2009). Two-dimensionally collapsed images were constructed from $Z$-stacks using ImageJ 1.42 software. The NeuronJ program was used for capturing neurites, at a preset line thickness, and the resulting lines were expressed as pixel numbers. Laminar distribution of the pixels was obtained from two to four sections of each cell and summed. The number of pixels was normalized, the sum of all bins being 1 for each cell. The distributions are in laminar bins; stratum radiatum was divided into three equal depth bins, and the other laminae represented one bin each. For histograms, the mean \pm SE of all reconstructed cells with axon and dendrites is shown.

The characteristics of antibodies were the same as published previously (Fuentealba et al., 2008; Oren et al., 2009; Nissen et al., 2010). The antibody to pro-CCK (polyclonal 1:500) was a gift from Dr. M. Watanabe (Department of Anatomy, Hokkaido University School of Medicine, Sapporo, Japan). Immunoreactions were analyzed in an AxioImager.Z1 microscope using confocal laser-scanning microscopy (LSM710 scanning head, Zeiss) and ZEN version 5.8 software. We applied spectral analysis of fluorophore (Alexa Fluor 488, Cy3, indodicarbocyanide Cy5, or DyLight649) emission for testing the specificity of signals and to exclude erroneous conclusions due to channel cross talk. Fluorophore-specific spectral peak amplitudes helped to evaluate the specificity of immunoreactions in cells using the QUASAR spectral detector. Axonal CB1R immunoreactions were analyzed with confocal or structured illumination.

Cell type identification. Ivy cells $(n=48)$ were identified as reported previously (Fuentealba et al., 2008). Seventeen of 33 tested cells were nitric oxide synthase positive (NOS+), or NOS + and neuropeptide-Y positive $(\mathrm{NPY}+)$. Eleven were only NPY + , and 5 were negative for both molecules, but identified from their characteristic dense axon with small boutons. Fifteen cells were damaged or the immunoreactions were not valid, and only characteristic axon clouds were recovered and used for identification.

The axons of O-LM cells $(n=21)$ projected from stratum oriens to distal stratum radiatum terminating in lacunosum moleculare (s.l.-m.). Their dendrites expressed filopodial spines. Some cells were tested for somatostatin (SM) (13 positive of 14 tested) and mGluR1 $\alpha$ (10 positive of 14 tested), two molecules expressed at high level in O-LM cells (Somogyi, 2010). In three cells, the axon was cut before it reached s.l.-m., but the molecular signature (two SM+ and mGluR $1 \alpha+$, one $\mathrm{SM}+$ ) and the dendritic tree suggested an O-LM cell. From one cell, only a typical axon was recovered.

Schaffer collateral-associated cells $(n=27)$ were identified by their axons distributed predominantly in layers of strata radiatum and oriens (see Fig. 2), immunopositivity for CB1R (27 of 27), and CCK+ soma (9 of 9 tested).
Single-cell RT-PCR. The cell's cytoplasm was aspirated into the recording pipette, and its content was expelled into a test tube. Reverse transcription and coamplification of GluA1-4 AMPAR subunit cDNAs were as described previously (Lambolez et al., 1992). The product of this first PCR was purified on a $1.5 \%$ low-melting-point agarose gel and used for quantification of the relative proportions of GluA1-4 and their flip/flop splice variants, as detailed earlier (Lambolez et al., 1996). The quantification of transcripts for GluA1-4 was performed via coamplification using a Cy5.5 fluorescently labeled antisense primer. Subunit-specific restriction digests of this second PCR product were resolved in separate lanes on agarose gel, and fluorescence was acquired and analyzed using the Odyssey infrared imaging system (LI-COR Biosciences). For each lane, the total fluorescence present in both the cut and the uncut peaks was normalized to $100 \%$. The percentage of fluorescence present in the cut peak thus represented the percentage of the corresponding subunit in the GluA1-4-amplified products. Quantification of the flip/flop proportion for each expressed subunit was performed similarly via subunitspecific amplification followed by splice variant-specific digests. Flip/flop proportions were then multiplied by the relative amounts of GluA1-4 subunits previously determined, to obtain the proportions of the GluA1-4 flip or flop expressed in each cell.

\section{Results}

Glutamatergic synapses onto NOS+ ivy cells and SM+ O-LM cells exhibit similar activity-induced long-term potentiation

We studied stimulus-evoked monosynaptic EPSPs in two afferent glutamatergic pathways to CA1 area hippocampal interneurons using the perforated patch method. After establishing a baseline, we applied TBS to one pathway. EPSPs were recorded for at least $30 \mathrm{~min}$ after TBS, followed by repatching in whole cell and filling with neurobiotin for post hoc anatomical analysis. Cell types were identified as described in Materials and Methods. Glutamate NMDARs and GABA receptors were blocked in all experiments.

Applying TBS to afferents to NOS + ivy cells in stratum radiatum elicited a $54 \pm 11 \%$ potentiation in the EPSP initial slope lasting at least $30 \min (p<0.01, n=6)$ and a $39 \pm 4 \%$ increase in amplitude $(p<0.01)$ (Fig. $1 A-C)$. Subsequent analysis reports the initial slope to rule out EPSP contamination by polysynaptic activity (Maccaferri and McBain, 1996). Ivy cells were recorded in current-clamp mode at resting membrane potential $(-66 \pm 2$ $\mathrm{mV}$ ), and they generally failed to fire action potentials during TBS $($ mean $=0.02$ spikes/stimulation pulse). Equally, TBS on afferents to SM+O-LM cells in stratum oriens evoked $50 \pm 7 \%$ EPSP potentiation $(n=6, p<0.01)$ (Fig. $1 D, E)$. TB stimuli applied at resting membrane potential $(-69 \pm 2 \mathrm{mV})$ elicited moderate postsynaptic firing (mean $=0.13$ spikes/stimulation pulse). Glutamatergic afferents to ivy cells were stimulated in stratum radiatum and to O-LM cells in stratum oriens. LTP in both cell types was similarly accompanied by an increase in $1 / \mathrm{CV}^{2}$ suggesting a presynaptic mechanism (Min et al., 1998) (Fig. $1 F)$.

When TBS was applied simultaneously with a postsynaptic depolarizing current step that enhanced postsynaptic spiking during TBS, LTP was compromised in both cell types. TBS applied at $-49 \pm 3 \mathrm{mV}$ to ivy cells with increased spiking ( $\mathrm{mean}=$ 0.43 spikes/stimulation pulse), produced nonsignificant $10 \pm 8 \%$ increase in mean EPSP $(n=5)$. Correspondingly, when spiking in O-LM cells was increased (mean $=0.68$ spikes/stimulation pulse) by depolarization, TBS (applied at $-52 \pm 2 \mathrm{mV}$ ) failed to induce potentiation in EPSPs (increase $6 \pm 7 \%, n=7$ ) (Fig. $1 C, E)$. These data from TBS in O-LM cells agree with earlier findings that used tetanic high-frequency stimulation (Oren et al., 2009; Le Duigou and Kullmann, 2011), whereas the data from ivy cells represent the first description of plasticity in these cells. 

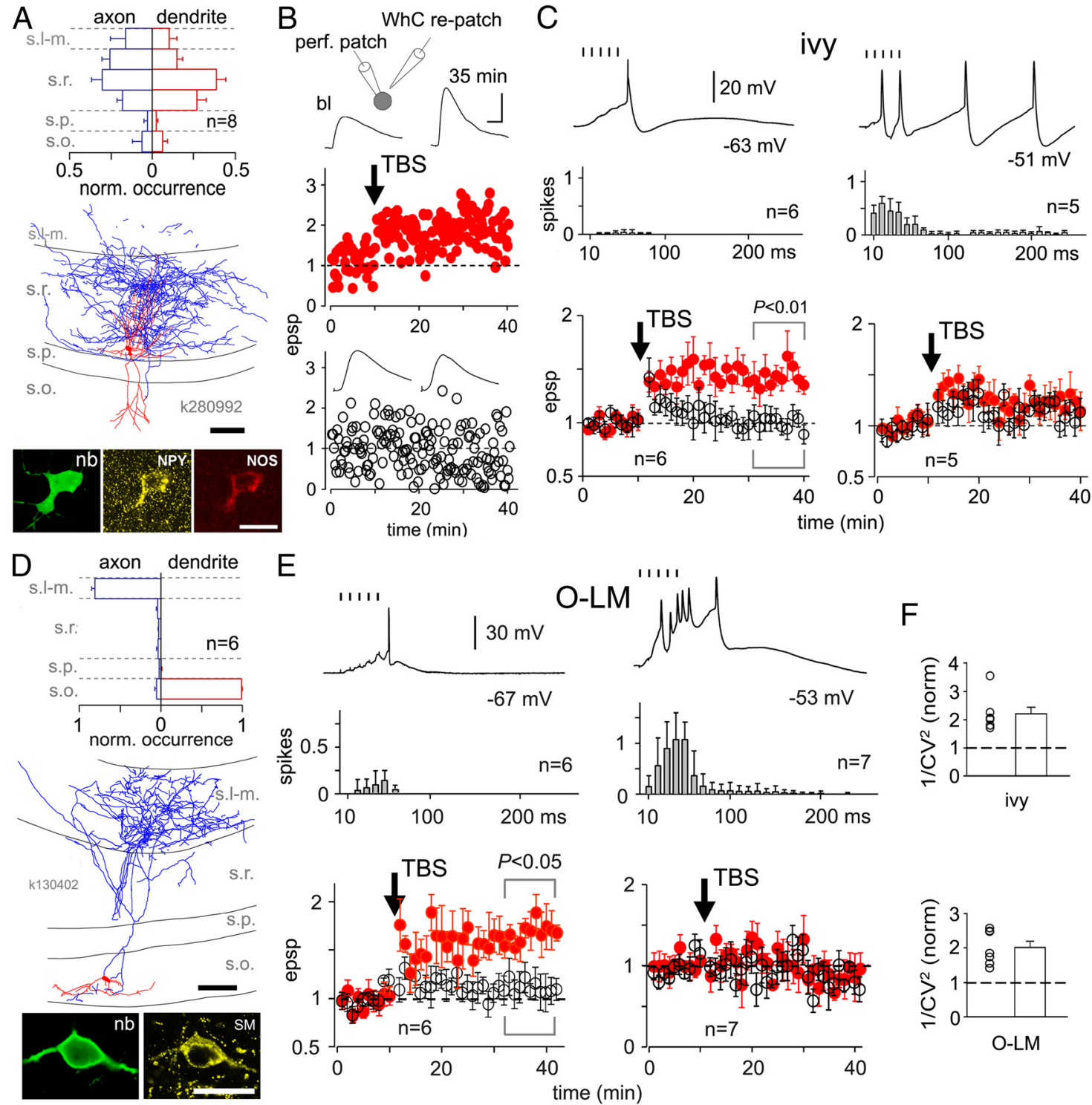

F

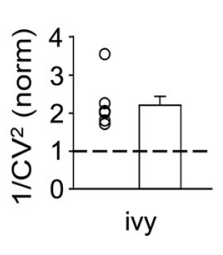

Figure 1. Similar LTP in ivy and 0-LM interneurons in the CA1 area. A, NOS-expressing ivy cells. Top, Averaged laminar distribution of the axons and dendrites of the population. Middle, One studied ivy cell visualized from a fluorescence image stack (soma, dendrites red; axon blue, scale $100 \mu \mathrm{m}$ ). Bottom, Confocal microscope images of neurobiotin (nb) and immunoreactivity for NOS and NPY. Scale bar, $20 \mu \mathrm{m}$. B, LTP elicited by TBS in one ivy cell. TBS ( $\downarrow$ ) applied to one pathway (red) elicits lasting potentiation in EPSP initial slope. Control pathway ( $\odot$ ) shows no change. EPSPs are baseline normalized. Insets, Averaged EPSP traces during baseline (bl) and at $35 \mathrm{~min}$ time point. Calibration: $4 \mathrm{mV} / 20 \mathrm{~ms}$. For labeling, the cell was repatched in whole cell and filled with neurobiotin (schematic). C, LTP in ivy cells shows inverse relationship to postsynaptic depolarization and spiking during afferent stimulation. Top, Action potentials (per afferent stimuli) in ivy cells where TBS was delivered at resting membrane potential (left) and in cells synchronously depolarized with current step (right). Insets show postsynaptic potential during a TBS (stimuli indicated on top). Bottom, left, Baseline-normalized EPSP initial slope (mean \pm SE) in ivy cells where TBS was applied at resting potential. Potentiation is specific to the TB-stimulated pathway and highly significant after $30 \mathrm{~min}(t$ test). Bottom, right, Similar experiments in ivy cells which were depolarized during TBS $(\downarrow)$ to enhance postsynaptic firing. This blocked LTP.D, SM-expressing 0-LM cells. Top, Average distribution of the axons (blue) and dendrites (red). Bottom, 0ne 0-LM cell. Scale bar, $100 \mu \mathrm{m}$. Confocal images show neurobiotin and positive immunoreaction for SM. Scale bar, 20 $\mu \mathrm{m} . \boldsymbol{E}$, TBS elicits LTP in 0-LM cells when delivered at postsynaptic resting potential (left), and potentiation is inhibited by depolarization and increased firing (right). Top, Postsynaptic potential and spikes induced by TBS. Bottom, Baseline-normalized EPSP shows LTP in TB-stimulated pathway (red) when applied $(\downarrow)$ at resting potential (left). Depolarizing current injection that increases postsynaptic firing compromises LTP (right). $\boldsymbol{F}$, Baseline-normalized $1 / \mathrm{CV}^{2}$ of EPSP initial slopes after potentiation ( $20-30 \mathrm{~min}$ ). Values indicate similarly presynaptic LTP expression mechanism in both interneuron types (bars, mean $\pm \mathrm{SE}$ ). norm., Normalized.

\section{LTP is interneuron type specific}

Compared with the above results, TBS failed to elicit LTP in Schaffer collateral-associated (SCA) cells. These interneurons express the neuropeptide CCK and axonal CB1R, and their axonal and dendritic laminar distribution overlap those of ivy cells in the CA1 area (Fig. 2 A). EPSPs were evoked by stimulation in stratum radiatum as in ivy cells. However, TBS applied to glutamatergic inputs to these cells failed to elicit a change in EPSP initial slope either when applied at resting membrane potential $(-66 \pm 2 \mathrm{mV}$, $n=5$; no spikes during TBS) or with postsynaptic firing elevated by depolarization (to $-49 \pm 3 \mathrm{mV}, n=5$; mean $=0.26$ spikes per stimulus) (Fig. $2 B$ ).

\section{CP-AMPARs are required for LTP in both ivy and O-LM cells}

To examine whether glutamatergic synapses onto ivy cells use CP-AMPARs, we recorded stimulus-evoked EPSCs in whole-cell voltage-clamp. The current-voltage $(I-V)$ relationship in the ivy cells revealed strongly inward-rectifying EPSCs, similar to those in O-LM cells (Fig. 3A). In contrast, EPSCs mediated by AMPARs in SCA cells exhibited a nearly linear $I-V$ relation, indicating 

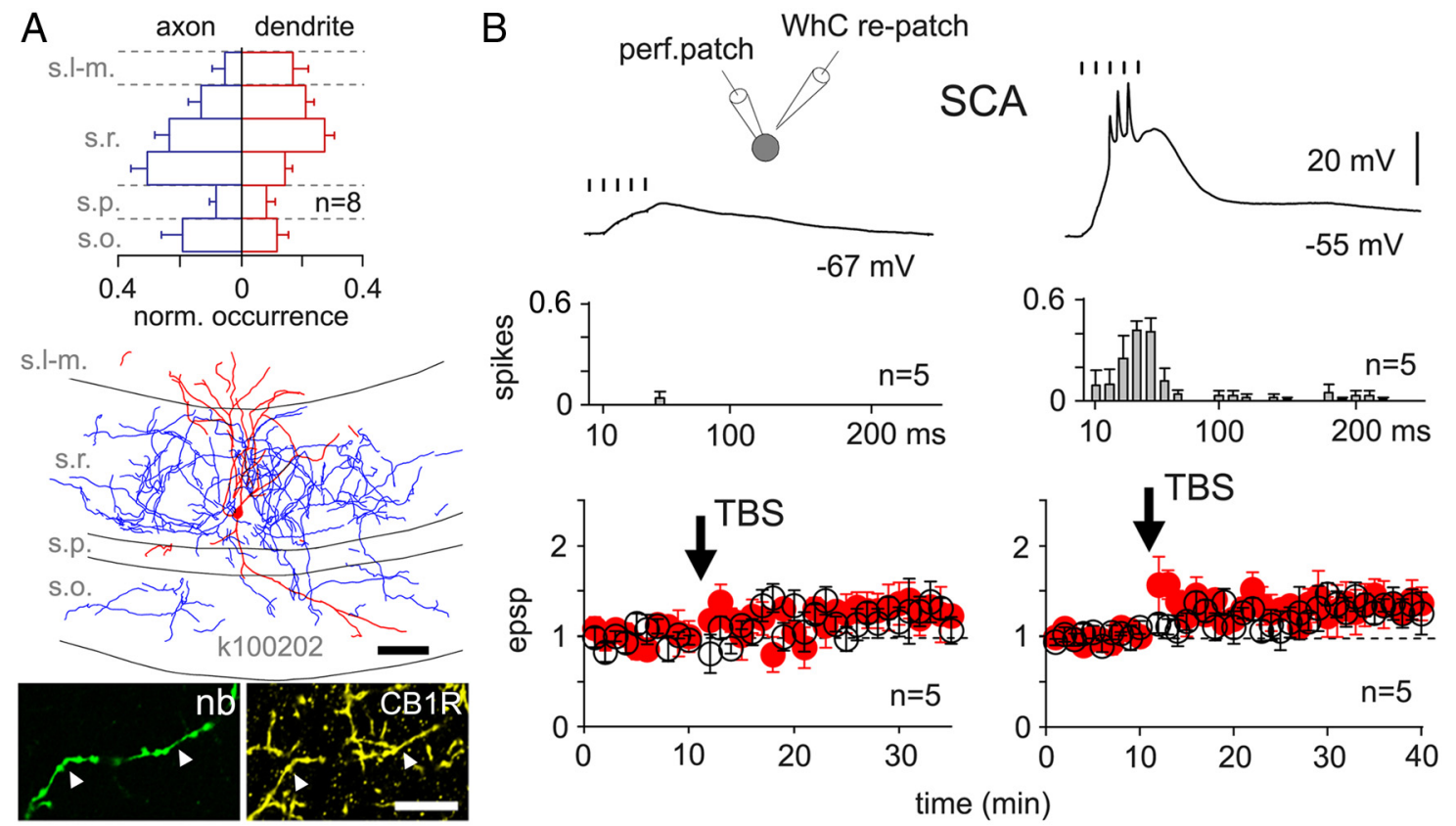

Figure 2. LTP is interneuron type specific. $A$, Top, SCA cells show similar averaged laminar distribution of the axons (blue) and dendrites (red) as ivy cells. Middle and bottom, A recorded SCA cell. Scale bar, $100 \mu \mathrm{m}$. Confocal images show positive immunoreaction for CB1R in the axon (arrowheads). Scale bar, $10 \mu \mathrm{m} . \boldsymbol{B}$, TBS ( $\downarrow$ ) fails to evoke LTP when delivered at resting potential or with postsynaptic depolarization to elicit firing. Top, Membrane potential changes during TBS at resting potential (left) and in a cell depolarized (right). Middle, Averaged spiking activity during TBS cycles in the two conditions. Bottom, Baseline-normalized EPSP initial slopes for TB-stimulated (red) and control pathways ( $~ \odot$ ). Cells stimulated at resting potential on the left and cells depolarized on the right. Cells were repatched for labeling (schematic). norm., Normalized; nb, neurobiotin; perf., perforated.

$\mathrm{Ca}^{2+}$-impermeable AMPARs (Jonas et al., 1994). To test the molecular basis underlying the inward rectifying EPSCs, we harvested cytosolic content for single-cell RT-PCR analyses and evaluated AMPAR subunit mRNAs (Fig. 3B) (Lambolez et al., 1992). Ivy cells ( $n=10$ cells) expressed mRNAs in the following ratio: GluA1 (81 $\pm 5 \%)$, GluA2 ( $\pm 4 \%)$, GluA3 (not detected), GluA4 $(11 \pm 5 \%)$. The low GluA2 expression level explains the strong inward rectification and calcium permeability of AMPARs in ivy cells (Jonas et al., 1994). In comparison, in SCA cells $(n=$ $9)$, the relative level of GluA2 was significantly higher $(31 \pm 12 \%)$ $(p<0.05)$, which is in line with their nearly linear $I-V$ relation. Both ivy cells and SCA cells expressed predominantly the flop splice variant of the subunits (Fig. 3B). Selective AMPA receptor antagonist GYKI53655 (25 $\mu \mathrm{M})$ effectively blocked EPSCs in all three cell types. EPSC amplitude was reduced by GYKI in ivy cells to $9 \pm 3 \%(n=6$ cells $)$, to $7 \pm 2 \%$ in O-LM cells $(n=8$ cells $)$, and in SCA cells to $9 \pm 2 \%$ ( $n=7$ cells). This confirms that CPAMPARs, and not kainate receptors, provide predominant inward rectifying fast glutamatergic transmission to these cells (Kamboj et al., 1995).

To test whether CP-AMPARs contributed to TBS-induced LTP in ivy cells, we recorded monosynaptic EPSPs in perforated patch as above, but after baseline washed in GYKI53655 (25 $\mu \mathrm{M})$ until AMPARs were blocked (Fig. 3C,D). TBS was then delivered to one of two stimulated pathways while the cell was at resting membrane potential (ivy: $-67 \pm 2 \mathrm{mV}, n=8$; O-LM: $-70 \pm 2$ $\mathrm{mV}, n=5)$. After the TBS, the GYKI was washed out and the recovery of EPSPs was followed for at least $30 \mathrm{~min}$. We observed no difference in the EPSP recovery between the TB-stimulated and control pathways, indicating blockade of LTP. The recovery was plotted as a ratio of baseline-normalized EPSPs in the TBstimulated versus control pathway, which was $0.87 \pm 0.02$ in ivy $(n=5)$ and $0.92 \pm 0.04$ in O-LM cells $(n=3)$ at 25-35 min after TBS. Release from AMPAR block allowed LTP induction again.
In separate experiments, EPSPs were blocked with GYKI as above and washed out before TBS was delivered. Significant potentiation was generated as indicated by stronger EPSP in the TBstimulated pathway than in the control pathway. TB-stimulated EPSPs were $43 \pm 4 \%$ larger than for the control pathway 25-35 min following the TBS ( $p<0.01, n=5$ cells, $n=3$ ivy and 2 O-LM cells) (Fig. 3E).

\section{Discussion}

We have demonstrated a similar glutamatergic synapse potentiation mechanism in two very different hippocampal GABAergic interneuron types, NOS + ivy cells and SM+O-LM cells. The potentiation in these cells is similarly input specific, requires $\mathrm{CP}$ AMPARs, lasts at least $30 \mathrm{~min}$, and is specific to interneuron types because it is not generated in CCK-expressing SCA cells. Ivy and O-LM cells have distinct developmental origin (Tricoire et al., 2011), and their main glutamatergic input originates from different pyramidal cell populations. Based on dendritic positions and stimulation sites, the inputs to ivy cells were dominated by afferents from the CA3 area, but those to O-LM cells by afferents from CA1 pyramidal cells (Somogyi, 2010). The similar LTP mechanism in these cells shows that CP-AMPARs lacking the GluA2 subunit provide a widespread molecular basis for synaptic plasticity in interneuron network.

Plasticity of input onto NOS-expressing ivy cells has not been reported earlier. LTP in both cell types was induced at the resting membrane potential, but it was strongly compromised if the cells were depolarized to fire simultaneously with glutamatergic synaptic activity. LTP induction at hyperpolarized postsynaptic potentials and its blockade by postsynaptic excitation have been shown previously in O-LM cells with tetanic high-frequency stimulation (Lamsa et al., 2007; Oren et al., 2009; Le Duigou and Kullmann, 2011). CP-AMPARs could allow postsynaptic calcium entry and plasticity induction by highly specific activity patterns different 

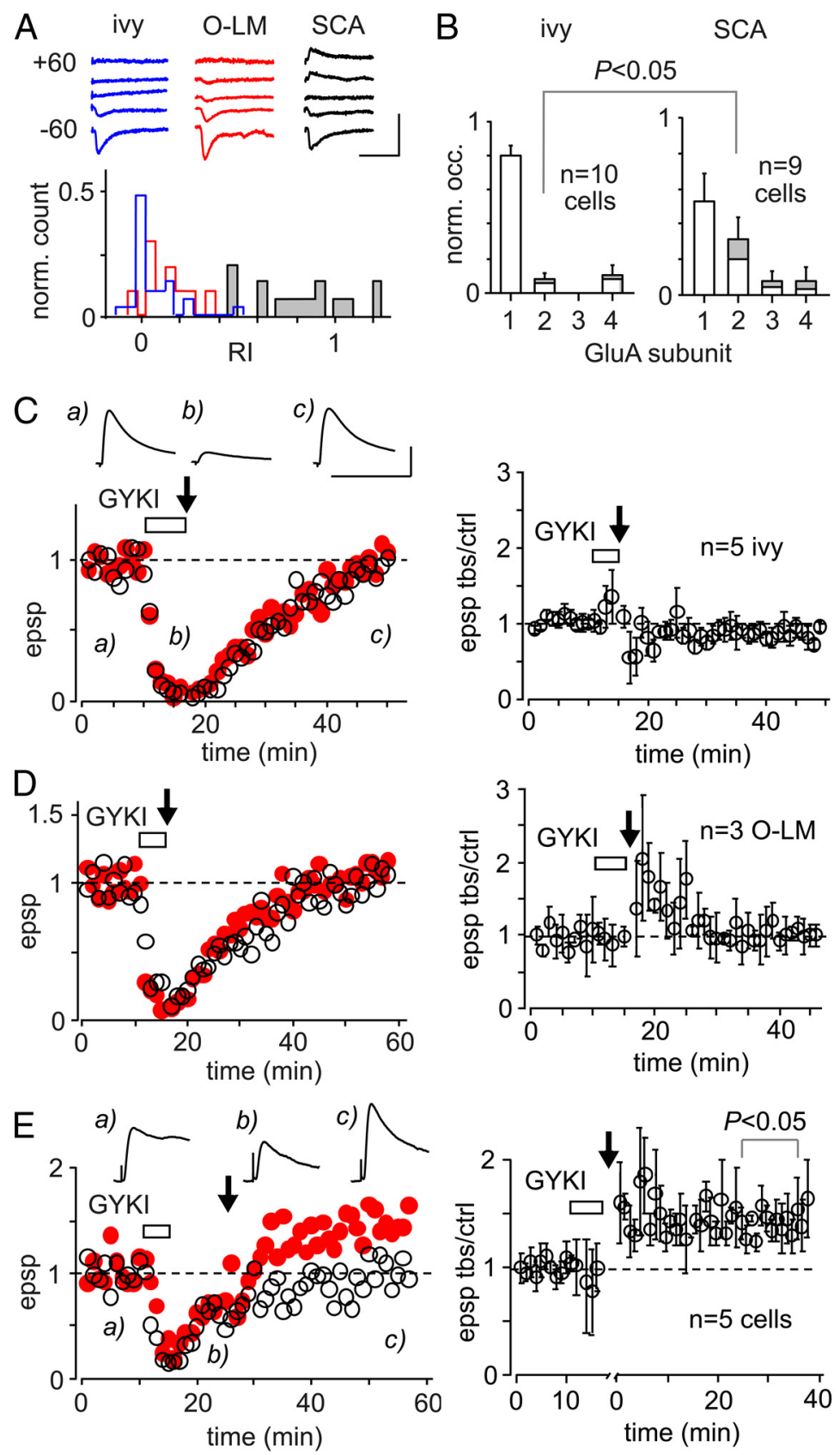

Figure 3. LTP in both ivy and 0 -LM cells requires (P-AMPARs. $A, B$, Synapses in ivy and 0 -LM, but not in SCA cells operate through (P-AMPARs. A, Ivy cells (blue, $n=17$ ) show strongly inward-rectifying stimulus-evoked synaptic EPSCs (whole cell), similar to 0 -LM cells (red, $n=5$ cells). In contrast, SCA cells (gray, $n=8$ ) exhibit only a minor rectification. Top, Sample EPSC traces at different membrane potentials (step $30 \mathrm{mV}$ ). Calibration: $50 \mathrm{pA} / 25 \mathrm{~ms}$. Bottom, Distribution of the rectification index (Rl; EPSC amplitude at $+60 \mathrm{vs}-60 \mathrm{mV}$ ). $\boldsymbol{B}$, Strength of EPSC rectification is associated with a low level of GluA2 expression. Relative abundance of AMPAR subunits GluA1-4 shown by single-cell RT-PCR analysis of mRNA in ivy and SCA cells. Ivy cells express low levels of the GluA2 in comparison with SCA cells ( $t$ test). Gray and open columns indicate the relative abundance of the flip and flop splice variants, respectively. C, LTP in ivy cells requires (P-AMPARs (perforated patch recordings). Left, Following baseline, EPSPs

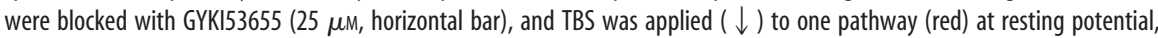
whereupon GYKI was washed out. Baseline-normalized plot shows no difference in recovery of the TB-stimulated and control pathway in 30 min. $\boldsymbol{a}-\boldsymbol{c}$, Averaged EPSPs traces evoked in the TB-stimulated pathway at marked time points. Calibration: 3 $\mathrm{mV} / 100 \mathrm{~ms}$. Right, Ratio of baseline-normalized EPSPs (TBS vs control pathway) in five ivy cells plotted during baseline, GYKI wash-in and wash-out. $\boldsymbol{D}$, Theta burst-induced LTP in 0-LM cells requires (P-AMPARs (perforated patch recordings). Similar experiments as in C repeated in 0-LM cells. Left, TB-stimulation to one pathway (red) and wash-out of GYKl in one 0-LM cell. Right, Ratio of baseline-normalized EPSPs (TBS vs control pathway) in three 0-LM cells. $\boldsymbol{E}$, Recovery from AMPAR block allows LTP induction. Left, Recording from an ivy cell. EPSPs were blocked, but GYKI was washed out before the TBS was applied ( $\downarrow$, red pathway), which induced significant potentiation in the TB-stimulated synapses. $\boldsymbol{a}-\boldsymbol{c}$, Averaged EPSP traces at time points show potentiation (scaling as in C). Right, Baseline-normalized EPSP ratio of the two pathways in three ivy and two 0-LM cells. In the abscissa, GYKI washout before TBS is not shown, because of variable washout times. norm., Normalized. from the NMDAR-dependent plasticity rules (Lamsa et al., 2007; Polepalli et al., 2010; Mameli et al., 2011). Synaptic activation of these receptors enables temporally highly accurate local calcium influx into interneuronal dendrites (Topolnik et al., 2005), and with their inverse voltagedependent conductance, could trigger postsynaptic calcium-dependent plasticity cascades at subthreshold membrane potential. Depolarization compromises CPAMPAR-mediated signaling via polyamine block and in addition dendritic backpropagating action potentials that regulate postsynaptic signaling cascades may suppress LTP in these conditions (Lamsa et al., 2007; Evstratova et al., 2011; Katona et al., 2011). Unlike pyramidal cells, these interneurons express mainly flop splice variants of AMPAR subunits. These are more susceptible than the flip variants to the influence of auxiliary intracellular proteins, which regulate EPSC conductance and kinetics (Jackson and Nicoll, 2011) and thus could also control CP-AMPAR-mediated LTP.

The induction of LTP in many interneuron types may be different from the NMDAR-dependent plasticity rules in pyramidal cells, in order for the interneurons to function as stable timing devices at specific oscillatory frequencies (McBain et al., 1999). For instance, during theta $(4-10 \mathrm{~Hz})$ and gamma frequency $(25-100 \mathrm{~Hz})$ rhythms associated with exploration and memory retrieval, ivy and O-LM cells fire repetitively in conjunction with their afferent CA1 pyramidal cells (Klausberger et al., 2003; Fuentealba et al., 2008; Czurkó et al., 2011). Lack of NMDAR-dependent plasticity (Perez et al., 2001; Oren et al., 2009) may allow these circuits to function as stable oscillators during such activity episodes, but to be modifiable via CP-AMPARmediated plasticity during sharp wave ripples (SWRs). Both ivy and O-LM cells are inhibited and spike little during SWRs when their afferent glutamatergic pyramidal cells discharge synchronously for 50-150 ms (Klausberger et al., 2003; Fuentealba et al., 2008), a condition that leads to LTP in these interneuron types. Dendritic inhibition strongly regulates signal input-output transformations in pyramidal cells (Lovett-Barron et al., 2012), and LTP of these inhibitory circuits may be required to preserve temporal integration properties of CA3CA1 connections (Lamsa et al., 2005). Plasticity of SCA interneurons, if present, may be triggered by other activity patterns and mechanisms or could be 
expressed predominantly in their efferent GABAergic synapses (Evstratova et al., 2011). A detailed account of the plastic behavior of GABAergic interneurons will require their investigation in the absence of any receptor blockers.

\section{References}

Czurkó A, Huxter J, Li Y, Hangya B, Muller RU (2011) Theta phase classification of interneurons in the hippocampal formation of freely moving rats. J Neurosci 31:2938-2947.

Evstratova A, Chamberland S, Topolnik L (2011) Cell-type-specific and activity-dependent dynamics of action-potential-evoked Ca2 + signals in dendrites of hippocampal inhibitory interneurons. J Physiol 589: 1957-1977.

Fuentealba P, Begum R, Capogna M, Jinno S, Márton LF, Csicsvari J, Thomson A, Somogyi P, Klausberger T (2008) Ivy cells: a population of nitric-oxideproducing, slow-spiking GABAergic neurons and their involvement in hippocampal network activity. Neuron 57:917-929.

Jackson AC, Nicoll RA (2011) The expanding social network of ionotropic glutamate receptors: TARPs and other transmembrane auxiliary subunits. Neuron 70:178-199.

Jonas P, Racca C, Sakmann B, Seeburg PH, Monyer H (1994) Differences in $\mathrm{Ca} 2+$ permeability of AMPA-type glutamate receptor channels in neocortical neurons caused by differential GluR-B subunit expression. Neuron 12:1281-1289.

Kamboj SK, Swanson GT, Cull-Candy SG (1995) Intracellular spermine confers rectification on rat calcium-permeable AMPA and kainate receptors. J Physiol 486:297-303.

Katona G, Kaszás A, Turi GF, Hájos N, Tamás G, Vizi ES, Rózsa B (2011) Roller Coaster Scanning reveals spontaneous triggering of dendritic spikes in CA1 interneurons. Proc Natl Acad Sci U S A 108:2148-2153.

Klausberger T, Magill PJ, Márton LF, Roberts JD, Cobden PM, Buzsáki G, Somogyi P (2003) Brain-state- and cell-type-specific firing of hippocampal interneurons in vivo. Nature 421:844-848.

Lambolez B, Audinat E, Bochet P, Crépel F, Rossier J (1992) AMPA receptor subunits expressed by single Purkinje cells. Neuron 9:247-258.

Lambolez B, Ropert N, Perrais D, Rossier J, Hestrin S (1996) Correlation between kinetics and RNA splicing of alpha-amino-3-hydroxy-5methylisoxazole-4-propionic acid receptors in neocortical neurons. Proc Natl Acad Sci U S A 93:1797-1802.

Lamsa KP, Heeroma JH, Somogyi P, Rusakov DA, Kullmann DM (2007) Anti-Hebbian long-term potentiation in the hippocampal feedback inhibitory circuit. Science 315:1262-1266.

Lamsa K, Heeroma JH, Kullmann DM (2005) Hebbian LTP in feed-forward inhibitory interneurons and the temporal fidelity of input discrimination. Nat Neurosci 8:916-924.
Le Duigou C, Kullmann DM (2011) Group I mGluR agonist-evoked longterm potentiation in hippocampal oriens interneurons. J Neurosci 31:5777-5781.

Lovett-Barron M, Turi GF, Kaifosh P, Lee PH, Bolze F, Sun X-H, Nicoud J-F, Zemelman BV, Sternson SM, Losonczy A (2012) Regulation of neuronal input transformations by tunable dendritic inhibition. Nat Neurosci 15:423-430.

Maccaferri G, McBain CJ (1996) Long-term potentiation in distinct subtypes of hippocampal nonpyramidal neurons. J Neurosci 16:5334-5343.

Mameli M, Bellone C, Brown MT, Luscher C (2011) Cocaine inverts rules for synaptic plasticity of glutamate transmission in the ventral tegmental area. Nat Neurosci 14:414-416.

McBain CJ, Freund TF, Mody I (1999) Glutamatergic synapses onto hippocampal interneurons: precision timing without lasting plasticity. Trends Neurosci 22:228-235.

Min MY, Asztely F, Kokaia M, Kullmann DM (1998) Long-term potentiation and dual-component quantal signaling in the dentate gyrus. Proc Natl Acad Sci U S A 95:4702-4707.

Nissen W, Szabo A, Somogyi J, Somogyi P, Lamsa KP (2010) Cell typespecific long-term plasticity at glutamatergic synapses onto hippocampal interneurons expressing either parvalbumin or CB1 cannabinoid receptor. J Neurosci 30:1337-1347.

Oren I, Nissen W, Kullmann DM, Somogyi P, Lamsa KP (2009) Role of ionotropic glutamate receptors in long-term potentiation in rat hippocampal CA1 oriens-lacunosum moleculare interneurons. J Neurosci 29:939-950.

Perez Y, Morin F, Lacaille JC (2001) A hebbian form of long-term potentiation dependent on mGluRla in hippocampal inhibitory interneurons. Proc Natl Acad Sci U S A 98:9401-9406.

Polepalli JS, Sullivan RK, Yanagawa Y, Sah P (2010) A specific class of interneuron mediates inhibitory plasticity in the lateral amygdala. J Neurosci 30:14619-14629.

Sambandan S, Sauer JF, Vida I, Bartos M (2010) Associative plasticity at excitatory synapses facilitates recruitment of fast-spiking interneurons in the dentate gyrus. J Neurosci 30:11826-11837.

Somogyi P (2010) Hippocampus: intrinsic organization. In: Handbook of brain microcircuits (Shepherd GM, Grillner S, eds), pp 148-164. New York: Oxford UP.

Topolnik L, Congar P, Lacaille JC (2005) Differential regulation of metabotropic glutamate receptor- and AMPA receptor-mediated dendritic $\mathrm{Ca}^{2+}$ signals by presynaptic and postsynaptic activity in hippocampal interneurons. J Neurosci 25:990-1001.

Tricoire L, Pelkey KA, Erkkila BE, Jeffries BW, Yuan X, McBain CJ (2011) A blueprint for the spatiotemporal origins of mouse hippocampal interneuron diversity. J Neurosci 31:10948-10970. 